\title{
Vloga posameznika pri spreminjanju javne uprave
}

\author{
UDK: 35.08 (497.12): 331.101 .3 \\ Janez Stare \\ Univerza v Ljubljani, Fakulteta za upravo \\ janko.stare@fu.uni-lj.si
}

\begin{abstract}
IZVLEČEK
Sodobni čas je čas hitrih sprememb, ki se kažejo na vseh ravneh družbenega in zasebnega življenja. Pomemben člen spreminjanja je javna uprava, ki s svojo (ne)aktivnostjo močno vpliva na delovanje in razvoj družbe. $V$ zvezi s proučevanjem vloge javnega uslužbenca in njegovega vpliva na spodbujanje učinkovitosti javne uprave se pojavlja vprašanje, ali je mogoče opredeliti dejavnike, ki bi bili z vidika spodbujanja učinkovitosti javne uprave načeloma primerni za vse ravni javnih uslužbencev. Gre za primer, ko v središče proučevanj postavimo javnega uslužbenca kot posameznika (ne glede na njegov položaj v sistemu delovanja javne uprave), ki s svojo držo in odnosom prispeva $k$ procesu spreminjanja javne uprave. Posameznikov prispevek je v veliki meri začrtan tudi na osnovi organizacijske kulture upravne organizacije.
\end{abstract}

Ključne besede: javna uprava, ravnanje s človeškimi viri, organizacijska kultura, javni uslužbenec, posameznik, učinkovitost.

\section{Uvod}

Vrsta razlogov narekuje posodobitev slovenske javne uprave, od zahteve po učinkovitejšem delovanju državnih institucij pa vse do skorajšnje vključitve v Evropsko unijo (EU). Prav proces približevanja Slovenije EU je prinesel številne zahteve po spremembah in prilagoditvah na vseh področjih našega dela in življenja. $V$ javnosti je (bilo) mogoče pogosto zaslediti številne komentarje o tem, kako pomembna je prilagoditev in priprava gospodarstva normam, standardom in pravilom, ki veljajo $\mathrm{v}$ krogu najrazvitejših evropskih držav. Ob tem se je kot rdeča nit vlekla »tradicionalna" kritika EU glede slovenske modernizacije in povečanja učinkovitosti delovanja javne uprave ter upravne usposobljenosti za uporabo pravnega reda EU. Komisija, ki je ocenjevala pripravljenost kandidatk, je pogosto opozarjala na nujnost nadaljnje reforme slovenske uprave. Le na tak način bi Slovenija lahko zgradila primerne strukture za učinkovito uporabo in uveljavitev pravnega reda EU. Mnenje komisije je opozorilo na potrebe po nadaljnjem razvoju upravne usposobljenosti in na potrebe po izboljšanju učinkovitosti in uspešnosti javne uprave. 
Izboljšanje učinkovitosti delovanja javne uprave mora postati del nove organizacijske kulture, ki izraža vsakodnevni trud zaposlenih pri spodbujanju učinkovitega delovanja javne uprave: vsakega na svojem področju dela. Pri tem je prispevek, ki ga daje vsak posamezen javni uslužbenec (v nadaljevanju posameznik), večji kot kdaj prej. Večji prispevek pa praviloma ne zadosti potrebam, saj so tudi pričakovanja do uprave in uslužbencev večja kot sploh kdaj.

Ob tem se pojavlja vprašanje, ali obstajajo posamezni vidiki spodbujanja učinkovitosti delovanja javne uprave, ki jih je mogoče opredeliti v splošnem za vse uslužbence ne glede na njihov položaj. $\vee$ prispevku želimo podati odgovor na zastavljeno vprašanje.

\section{Pot do učinkovitosti je v spreminjanju javne uprave}

S pojmom javna uprava opredeljujemo organe in organizacije, ki opravljajo javne zadeve oz. izvajajo dejavnost upravljanja $v$ javnih zadevah. Javna uprava se deli na državno upravo, lokalno samoupravo, javne službe in javni sektor. Zajema vse dejavnosti javnega upravljanja ne glede na to, ali jih opravljajo državni upravni organi ali organizacije izven državnega mehanizma, in ne glede na to, ali nastopajo oblastno ali neoblastno. Javna uprava zajema vse državne in paradržavne organizacije, organe in službe, razen sodnih.

Javna uprava je zelo pestra po dejavnosti in številna po deležu aktivnega prebivalstva, ki ga zaposluje. Sodi med pomembnejše usmerjevalce družbenega razvoja, za svoje delovanje pa potroši zajeten del državnega proračuna. " $\vee$ dvajsetem stoletju je javni upravi dajalo pečat pravo. To velja zlasti za kontinentalno Evropo, medtem ko $v$ anglosaksonskih državah pridejo do izraza tudi druge znanstvene discipline. Sodobna raziskovanja javne uprave pa vse bolj v ospredje postavljajo interdisciplinarni pristop. To še posebej velja za organizacijske vede, ki morajo pri raziskovanju javne uprave upoštevati pravno-politične temelje, človeške vire, tehnologijo, zahteve po učinkovitosti in ekonomičnosti in podobno." (Brejc, 2000, str. 9.)

Slovenija se je v procesu približevanja EU obvezala, da bo oblikovala sodoben sistem javne uprave. To pa je težavna naloga, saj se število funkcij javnega sektorja zadnja desetletja nenehno povečuje; ne samo pri nas, ampak $\vee$ vseh sodobnih družbah. Javna uprava mora izpolnjevati potrebe po vse večji povezanosti različnih področij dela, spremembi aktivnosti in načinu dela, predvsem pa zahteve po večji učinkovitosti upravnega dela. Vse to pa povzroča tudi količinsko rast uprave. Prav na rast uprave se nanaša ena izmed najpogostejših kritik javnosti do uprave, češ da je uprava neučinkovita zato, ker je številčno preobsežna. "Količinska rast uprave ni nujno negativen pojav, saj se s širjenjem uprave povečuje obseg in kakovost uslug 


\section{Janez Stare}

\section{Vloga posameznika pri spreminjanju javne uprave}

in storitev javne uprave. Ključno in najtežje vprašanje pa je, koliko uprave je treba za dani obseg in kompleksnost nalog. Na to vprašanje niti znanost niti praksa še nista našli ustreznega odgovora. Zato je tudi vprašljivo govorjenje o tem, da je uprave preveč, če ob tem ne povemo, koliko bi je bilo ravno prav." (Brejc, 2000, str. 20)

Vprašanje učinkovitosti uprave je spodbujeno tudi zaradi spreminjajočega se položaja, ki ga ima uprava $\vee$ družbi. Iz represivne in regulativne uprave, ki je bila podaljšana roka oblasti in je zagotavljala predvsem javni red in mir, se je njeno delovanje razvijalo in razširilo na praktično vsa področja človekovega družbenega življenja. To pa od javne uprave in zaposlenih zahteva na eni strani znanje, učinkovitost, racionalnost, prilagodljivost in inovativnost, na drugi strani pa tudi spremenjeno strukturo delovanja javne uprave in drugačno organizacijsko kulturo.

Spreminjanje in povečevanje učinkovitosti je mogoče z opuščanjem birokratske organizacije (Webrovega tipa), ki je najpogostejša prav na področju javne uprave. Pri birokratski organizaciji gre za idejo, da se iz funkcioniranja organizacije izključi človeška nezanesljivost (vse se definira z izčrpnimi pravili). Poleg tega se zahtevajo jasna delitev dela, močna stopnja hierarhije, selekcija zaposlenih in napredovanje na osnovi tehničnih sposobnosti ter popolno ločevanje osebnega in organizacijskega življenja.

Zaradi predpostavke, da organizacija deluje kot zaprt sistem, ki ne vsebuje mehanizmov prilagajanja spremembam $v$ okolju, organizacija Webrovega tipa ni več kos novim razmeram na področju javne uprave. Neustrezni pa so tudi strogo formalni in strogo hierarhično urejeni odnosi med zaposlenimi, ki jih takšen način organiziranja predpostavlja.

Vse več teoretikov in praktikov govori o tem, da mora javna uprava pričeti delovati po načelih poslovne uspešnosti in $v$ bistvu postati poslovni sistem. $S$ tem seveda ne bodo rešeni vsi problemi, s katerimi se javna uprava srečuje, omogočena pa bo večja uspešnost in učinkovitost. $V$ javnih upravah razvitih demokracij je še posebej $\vee$ zadnjem desetletju zelo pogosto uvajanje načel novega javnega menedžmenta (NJM; New Public Management - NPM).

NJM predpostavlja, da je treba $\vee$ delovanje javne uprave uvesti pozitivne izkušnje menedžmenta zasebnega sektorja. Na tak način je mogoče pričakovati, da bo tudi javna uprava sposobna dosegati in prevzemati značilnosti uspešnih organizacij. Kovač (1999, str. 31) tako meni, da NJM sestavlja niz konceptov, tehnik in načel, ki s ciljem splošne učinkovitosti uprave težijo k vpeljavi pozitivnih elementov iz upravljanja in delovanja zasebnega sektorja.

Omenjene značilnosti se kažejo $v$ hitrem reagiranju na postavljene naloge ali spremenjene razmere, usmerjenosti v akcije ter izvajanju dejavnosti, ki so usmerjene $\mathrm{k}$ uporabniku in rezultatu. Za to je potrebno poznavanje in razumevanje potreb in zahtev uporabnika (državljana), kar končno kaže tudi na povezanost organizacije z uporabniki njenih storitev. 
Uspešne organizacije imajo izoblikovane sisteme motiviranja, s katerimi stalno skrbijo za ustrezno motivacijo zaposlenih, s tem pa povečujejo produktivnost oz. učinkovitost dela. Zaposlenim dajejo občutek spoštovanja in koristnosti, skrbijo za njihov razvoj ter jim omogočajo napredovanje. Zaposleni opravljajo tiste naloge, ki jih obvladajo najbolje. Pri delu se spodbujajo ustvarjalnost, podjetniški duh in oblikovanje skupnih ciljev. $\vee$ uspešnih organizacijah se poudarjata zanesljivost pri opravljanju dela in pomen posameznih opravil, ki jih opravljajo zaposleni.

Nadzora nad izvajanjem nalog je $v$ uspešnih organizacijah malo, vendar je ta stalen in oster. Organizacijska struktura je enostavna, z malo birokracije in malo štabnih funkcij. Vodstvo je $v$ stalnem stiku z zaposlenimi, komunikacija pa poteka $v$ obe smeri, tako da zaposleni poznajo poslovno filozofijo organizacije, ki je razmeroma stabilna in imajo jasno predstavo o lastni organizaciji.

Kot je že omenjeno, bi želeli opisane značinosti čim bolj razviti tudi $\vee$ javni upravi. Pri tem je treba vseskozi upoštevati specifično situacijo v javni upravi, saj se državljani pojavljajo $v$ vlogi lastnikov, financerjev in končnih uporabnikov storitev. Seveda pa zavedanje o tem lahko le še bolj spodbudi procese spreminjanja javne uprave in prizadevanje za povečanje učinkovitosti.

\section{Vloga posameznika $v$ procesih spodbujanja učinkovitosti javne uprave}

Večina avtorjev, ki se ukvarja s proučevanjem učinkovitosti v javni upravi, poudarja, da na učinkovitost upravnega dela in spodbujanje te učinkovitosti vpliva veliko dejavnikov. To utemeljuje z dejstvom, da morajo upravne organizacije, če hočejo biti uspešne, zagotoviti veliko učinkovitost opravljanja dejavnosti v vseh delih poslovnega procesa. S tem se poveča pomen znanja in ravnanja vseh zaposlenih. Takšen pristop zahteva tudi merila, s katerimi je mogoče kakovost in učinkovitost opravljanja posameznih dejavnosti sproti preverjati ter hkrati zagotoviti, da šibki členi ne ovirajo rasti in delovanja celotnega sistema.

O učinkoviti javni upravi govorimo torej takrat, kadar dosega zastavljene cilje, izvršuje svoje delo v najkrajšem možnem času, opravlja delo brez napak, zaznava in se ekspeditivno odziva na potrebe okolja itd. Uprava bo lažje postala takšna, če bodo učinkovitost kot vrednoto sprejeli vsi zaposleni.

Res je, da je prispevek posameznika k spreminjanju javne uprave in $\mathrm{k}$ spodbujanju učinkovitosti precej določen z odnosom uprave do posameznika in z delom, ki ga posameznik opravlja, to je s položajem, ki ga zaseda $v$ sistemu javne uprave. Poleg tega je precej aktivnosti opredeljenih s politiko, ki na posameznem področju delovanja javne uprave definira ravnanje. Kljub temu pa velja, da bo uprava postala učinkovitejša le, če bodo učinkovitost delovanja spodbujali vsi zaposleni. Lahko 


\section{Janez Stare}

\section{Vloga posameznika pri spreminjanju javne uprave}

rečemo, da gre tudi za spreminjanje organizacijske kulture, kar je zahteven proces. Strukture (predpise) je razmeroma lahko spreminjati. Težko je spreminjati ljudi.

Vpliv odnosa uprave do posameznika je z vidika prispevka, ki ga daje posameznik $k$ procesu učinkovitosti uprave, težje opredeljiv. Čeprav se je odnos uprave do posameznika $\vee$ upravi spreminjal, pa je še vedno razmeroma težko enoznačno opredeliti, kaj je tisto, kar posameznika spodbudi za uspešno in učinkovito delo. Odločitev in aktivnost je močno odvisna od značaja in osebnosti posameznika. Tako bo $\mathrm{npr}$. zanesljivost in varnost zaposlitve $v$ tradicionalni upravi ter lojalnost sistemu kot ena izmed najvišjih vrednot kljub paternalističnemu odnosu uprave do zaposlenih $\checkmark$ nekaterih primerih delovala spodbudno, $v$ drugih pa povsem zavirajoče - in nasprotno. Pričakovana participacija in prevzeta soodgovornost za lastno delovanje, ki jo spodbuja NJM, bo pri posamezniku, ki ni pripravljen ali zmožen prevzemati odgovornosti, delovala predvsem zavirajoče in demotivirajoče.

Vloga posameznika je $v$ procesu spodbujanja učinkovitosti javne uprave zelo velika predvsem iz dveh razlogov. Prvi je ta, da je delo posameznika strokovno vedno na višji ravni. Tako s svojim delom močno vpliva na potek in uspešnost delovanja javne uprave. Tudi zato so posamezniki vedno bolj cenjeni, zaradi vpliva na organizacijske procese pa pridobivajo tudi ustrezno avtoriteto.

Drugi razlog je dejstvo, da je delo posameznika vse bolj vpeto med različna področja poslovanja javne uprave. Časi, ko je imel posameznik določeno eno samo vrsto dela, so minili. Posamezniki ne opravljajo več samo dela, vezanega na eno delovno nalogo, ampak opravljajo vse več nalog, ki so vezane na različne delovne postopke, procese in dejavnosti. $\mathrm{S}$ tem pa raste tudi odgovornost posameznika glede spodbujanja učinkovitosti upravnega dela. Heraty in Morley (1998, str. 663) menita, da je poglavitna razlika med uspešnimi in neuspešnimi organizacijami v zaposlenih in njihovem načinu dela. Poleg tega sta mnenja, da pomenijo individualne sposobnosti zaposlenih največjo konkurenčno prednost.

Vidikov, s katerih posameznik najočitneje vpliva na spodbujanje učinkovitosti javne uprave, je več. Lahko jih razdelimo $v$ pet osnovnih skupin, ki opredeljujejo delo in odnos posameznika do:

- sebe,

- lastnega dela,

- organizacije,

- sodelavcev,

- delovnega okolja.

Posamezne vidike $v$ nadaljevanju obravnavamo ločeno, čeprav so $v$ upravni praksi med seboj precej povezani. 


\subsection{Odnos posameznika do sebe}

Razvijanje odnosa do sebe je največji izziv posamezniku sodobnega sveta. Hkrati je to tudi pogoj, da bo posameznik sploh lahko spremljal hiter razvoj javne uprave in enakopravno sodeloval v spremenjenih delovnih razmerah. Gre za naravnanost posameznika k stalnemu izpopolnjevanju na vseh življenjskih področjih. Kranjc (1982, str. 116-125) meni, da posameznik pridobiva motivacijo za izobraževanje že $v$ otroštvu z družinsko vzgojo, z mnenjem staršev, s splošnimi pogledi, odvisna pa je tudi od zadovoljevanja osnovnih materialnih potreb. Le z zavedanjem sebe, vrednosti izobraževanja in usposabljanja, s pridobljenim znanjem, sposobnostjo in veščinami lahko pričakujemo ustrezen prispevek posameznika k spodbujanju učinkovitosti.

Pri tem gre za povečevanje sposobnosti posameznika na vseh področjih življenja in dela. Gre za idejo vseživljenjskega izobraževanja, za to, da znanje in usposobljenost postaneta vrednota. Seveda je samo izobraževanje premalo. Gre za celotno področje človekovih lastnosti in zmožnosti, ki jih lahko definiramo na treh nivojih:

- kot sposobnosti in predispozicije ali tisto, kar posameznik zmore,

- kot navade, spretnosti in znanje ali tisto, kar posameznik zna,

- kot interesi, nagnjenja, stališča ali tisto, kar posameznik hoče.

Pri tem je treba omeniti, da je možnost lastnega vplivanja na navedene lastnosti različna, včasih je večja, drugič zelo majhna. To še posebej velja za sposobnosti in predispozicije, saj sposobnosti niso rezultat specifičnega usposabljanja na nekem področju (pri usposabljanju gre že za znanje ali veščino), ampak so nekakšne človekove prikrite zmožnosti, da si pri usposabljanju za neko delo pridobi znanje in veščine.

Večji vpliv ima posameznik na druge navedene lastnosti: navade, spretnosti in znanje, ki jih lahko pridobiva z lastno dejavnostjo. Gre za pridobivanje formalne izobrazbe $v$ zavodih in drugih izobraževalnih organizacijah kot tudi za pridobivanje znanja, veščin in spretnosti na različnih srečanjih, posvetovanjih, seminarjih ipd.

Interese, nagnjenja in stališča lahko opredelimo kot motivacijo posameznika za opravljanje dela. Omeniti moramo, da obstajata splošna in posebna motivacija za delo. Nekdo ima npr. lahko nizko splošno motivacijo, ima pa zato posebne motive za neko delo. Večje možnosti ima tisti posameznik, ki ima visoko splošno motivacijo, saj navadno dosega $v$ vseh dejavnostih primerne rezultate - to pa je za spodbujanje učinkovitosti pomembno dejstvo. Motivi spodbujajo posameznika k dejavnosti in sposobnosti, spretnosti in znanje pa mu omogočajo, da svoje aktivnosti uspešno izvede. Omenjenih treh dejavnikov zato ne smemo izključevati, saj so vsi trije potrebni za uspešnost pri delu in s tem za večjo možnost vplivanja na učinkovitost lastnega dela in dela $v$ javni upravi. 
Janez Stare

Vloga posameznika pri spreminjanju javne uprave

Pri odnosu posameznika do sebe lahko upoštevamo tudi posameznikovo upoštevanje etičnih načel, ki veljajo $v$ zunanjem in notranjem delovnem okolju. Brejc (2002, str. 74) meni, da je pripravljenost upoštevati etična načela odvisna od:

- obsega sprejemanja vrednot organizacije. Čim bolj se posameznik identificira z vrednostnim sistemom organizacije, tem bolj bo pripravljen delovati skladno z etičnimi načeli te organizacije;

- skladnosti ciljev posameznika in organizacije;

- pomena dela, ki ga opravlja;

- presoje, ali organizacija zagotavlja zadostne možnosti za razvoj posameznika.

Brejc tudi meni (2002, str. 76), da se prav v zvezi z etičnostjo delovanja pojavlja eno temeljnih vprašanj sodobne javne uprave, tj. iskanje odgovora na vprašanja, kako se odzvati na razvojne spremembe, kako tradicionalne vrednote povezati z novimi pristopi, kako $v$ etičnem kodeksu upoštevati značilnosti NJM, skratka, kako zaposlenim dati dovolj jasne napotke, kako naj ravnajo.

\subsection{Odnos posameznika do lastnega dela}

Kadar govorimo o odnosu posameznika do lastnega dela kot o dejavniku spodbujanja učinkovitosti javne uprave, merimo predvsem na opredelitev ključnih področij njegovega dela, delovnih nalog in pravil, ki jih mora upoštevati pri delu. Kako jih upošteva in kakšen je prispevek posameznika, pa je treba preverjati s perspektive etičnosti opravljenega dela.

Seveda pa poleg tega ne moremo mimo že povedanega: skrbi posameznika za lastni razvoj. Razlika je torej $v$ tem, da nas pri odnosu posameznika do samega sebe zanima usposabljanje in splošna kompetentnost, pri odnosu posameznika do lastnega dela pa ustrezna usposobljenost za delo, ki ga posameznik trenutno opravlja. Delo samo je pomemben motivacijski dejavnik, ki na različnih ravneh spodbudi posameznika k razvoju ali odločitvi za lastni razvoj na delovnem področju. Prav tako lahko povzroči, da posameznik ne vidi pomena in smisla lastnega razvoja. Jelenc (1996, str. 45) meni, da je vsaj tako pomembno kot poznati motive odraslih za izobraževanje tudi vedeti, kaj odrasle ovira, da se ne odločijo za izobraževanje.

$\checkmark$ zvezi s tem se kot pomemben dejavnik učinkovitosti upravnega dela omenja kakovost dela. Definiranje kakovosti ni enostavno, saj so znane različne ideje glede pomena posameznih dimenzij za kakovost upravnega dela. $\vee$ splošnem lahko kakovost dela posameznika opredelimo kot doseganje in preseganje predenj postavljenih zahtev glede opravljanja posameznega dela, doseganja rezultatov opravljanja storitev; vse to na tak način, da bo posameznik s svojim delom izpolnil cilj (javne uprave) ter hkrati zadostil potrebam strank (javnosti, državljana itd.). 


\subsection{Odnos posameznika do organizacije (javne uprave)}

Če posameznik želi kar največ prispevati k povečanju učinkovitosti javne uprave, mora poznati delovanje in sistem javne uprave. Razumeti mora cilje delovanja upravne organizacije, v kateri dela, ter seveda cilje svojega oddelka, svojega delovnega mesta in tudi cilje delovanja svojega nadrejenega.

Omenjene zahteve bo mogoče doseči, če so cilji delovanja jasno definirani in poznani zaposlenim. Pri tem je treba opozoriti, da so smiselna samo tista dela, ki so $\checkmark$ funkciji doseganja postavljenih ciljev javne uprave ali konkretne upravne organizacije. Brez poznanih ciljev delovanja ni mogoče določiti vsebine dela. če ne vemo, zakaj delati, ali če vemo, da delo ne omogoči doseganja ciljev, zakaj bi potem delo sploh opravljali in se trudili s povečanjem učinkovitosti takšnega dela?

Jasno definiranje cilja delovanja organizacije, lastnega dela in znana pravila delovanja bodo pripomogli $k$ temu, da bo posameznik vedel, kaj se od njega pričakuje, kaj je kriterij učinkovitosti in uspešnosti njegovega dela ter kaj poveča uspešnost upravnega dela.

Poleg poznavanja sistema javne uprave je treba poznati tudi osnovne etične vidike, sistem vrednot, normative in principe delovanja konkretne upravne organizacije ter način izvajanja njenih osnovnih funkcij organiziranega delovanja. Z vidika dejavnosti in narave dela gre predvsem za ustrezno razumevanje upravne funkcije, ki jo sestavljajo: načrtovanje, organiziranje, ukazovanje, usklajevanje in nadzorovanje.

Načrtovanje pomeni stalno raziskovanje in predvidevanje prihodnosti. Gre za to, da se z namenom uresničitve določenega cilja opredeli potrebno delo. Pri tem je nujno dobro poznavanje situacije in napovedi za prihodnost, poznavanje in prepoznavanje možnih težav, določanje ciljev ipd.

Zagotavljanje vsega potrebnega za funkcioniranje upravne organizacije poteka $\checkmark$ okviru funkcije organiziranja. Pri tem gre tako za področje materialnega (materiali, oprema, kapital) kot tudi socialnega (ljudje). $\vee$ okviru te funkcije je treba zagotoviti smiselno oblikovanje delovnih ciljev in delovnih načrtov, določiti dejavnosti za doseganje oblikovanih ciljev, uskladiti vse vire, ki so potrebni za doseganje ciljev, jasno določiti pristojnosti in odgovornost posameznikov, zagotoviti pooblastila za izvajanje nalog, skrbeti za to, da so interesi posameznika podrejeni interesom upravne organizacije, itd.

Čeprav ima samo ukazovanje dostikrat negativni predznak, pa velja, da gre le za izvrševanje dogovorjenega načina vodenja. S tem navadno označujemo način, kako vodja vpliva na posameznika ali skupino, da opravi neko delo.

Usklajevanje dela se kaže $v$ usklajenem delovanju posameznikov ali različnih organizacijskih oblik (oddelkov, organov ipd.). Usklajeno delovanje je možno le ob poznavanju lastne vloge $v$ procesu dela, povezanosti med posameznimi subjekti in skupnimi interesi delovanja. 


\section{Janez Stare}

\section{Vloga posameznika pri spreminjanju javne uprave}

Nadzorovanje je preverjanje dejanskega stanja z načrtovanim stanjem, zastavljenimi cilji, predvidenimi programi poslovanja in danimi pravili. Gre za sprotno ugotavljanje odstopanja od predvidenega stanja, to pa zato, da bi lahko pravočasno sprejeli ukrepe, s katerimi bi odstopanja odpravili. Nadzor lahko izvedemo z razgovorom, s primerjavo doseženih rezultatov z načrti, z zakonskimi določili ipd.

Odnos do organizacije zajema tudi odgovoren odnos do virov. Kljub temu da $v$ upravi pogosto zasledimo mnenje, da je ustrezna skrb za ravnanje $z$ viri predvsem stvar vodstva, pa to ne drži. Za učinkovito ravnanje z viri je odgovoren vsak posameznik. Tako lahko Everardovo in Morrisovo ugotovitev, ki sta jo sicer opredelila za vodje oz. menedžerje, razumemo tudi kot vodilo za vsakega posameznika. Omenjena avtorja pravita (Everard, 1996, str. 23), da vsaka organizacija pričakuje od svojega menedžerja vsaj troje:

1. da bo povezoval razpoložljive vire tako, da bo dosežen cilj,

2. da bo glavni dejavnik uspešnih sprememb,

3. da bo vzdrževal in razvijal razpoložljive vire.

Odnos do virov upravne organizacije in ravnanje z njimi je pomemben vidik odnosa posameznika do upravne organizacije, posledično pa seveda vpliva na učinkovitost upravnega dela.

\subsection{Odnos posameznika do sodelavcev}

Ustrezen odnos do sodelavcev pripomore k ustreznemu odzivanju, sodelovanju in spodbujanju med sodelavci. S tem je omogočeno povečanje učinkovitosti javne uprave. Ustrezen odnos do sodelavcev je običajno opredeljen s temeljnimi komunikacijskimi vrednotami. Mednje štejemo spoštovanje, poslušanje, zavedanje in sprejemanje odvisnosti od drugega.

Medsebojni odnos lahko najučinkoviteje vzpostavimo z ustrezno komunikacijo. Zanjo je ( $v$ odnosu do sodelavca) potrebno zavedanje in poznavanje samega sebe, razvijanje občutka medsebojnega zaupanja, sprejemanje povratnih informacij in pogovor o odnosu.

Za kakovostno komunikacijo morajo biti izpolnjeni štirje temeljni pogoji (Brajša, 1993, str. 94-95):

1. svoboda (pri izbiri partnerja, vsebine, prostora, časa),

2. neogroženost lastne osebnosti (avtonomnost, nedotakljivost, vrednost, svetost osebne integritete),

3. sprejemanje komunikacije vseh sogovornikov,

4. komunikacijska iskrenost.

Bistveno za uspešno komuniciranje je obvladovanje motenj. Razumevanje med pošiljateljem in prejemnikom sporočila je ključ do rešitve. Sporočilo je dobro 
večkrat ponoviti, nepogrešljive so povratne informacije prejemnika pošiljatelju. Thorrington in Hall (Thorrington, 1995, str. 126-141) trdita, da o komuniciranju lahko govorimo samo takrat, kadar gre tako za posredovanje sporočila ene osebe kot tudi sprejem in razumevanje sporočila pri drugi osebi. Sporočilo - ne glede na to, kako pomembno je - je nekoristno toliko časa, dokler ni sporočeno (posredovano) in razumljeno pri drugih (Robbins, 1998, str. 310).

Pri odnosu do drugih in želji po povečanju učinkovitosti gre tudi za vprašanje, kdo in kako mi lahko pomaga pri mojem socialnem učenju, npr. kdo mi bo povedal moje napake, da me ne bo prizadel, od koga sploh lahko pričakujem kritiko, kaj bi lahko pri sebi spremenil, kako pomembno je za lastni osebnostni razvoj in izobrazbo vedenje o samem sebi itd.

Odgovor na to vprašanje je pomemben z več vidikov. Pogosto namreč posameznik ne ve nič o tem, kakšen vtis naredi na druge. Lahko ga ocenjujejo dobro, lahko pa tudi slabše, kot si zasluži in kot je res. Zato je tudi podoba, ki jo razvija o sebi, dostikrat drugačna od tiste, ki jo imajo drugi o njem. Če je razlika med tema dvema podobama prevelika, se lahko zgodi, da bo posameznik naletel na oviro, s tem pa se lahko za nekaj časa zavre učinkovitost njegovega delovanja.

Prav vprašanje odnosa je dostikrat krivo, da se nobeden ne potrudi, da bi sodelavcu zagotovil povratne informacije ali jih ustrezno doziral. Temu lahko dodamo še hierarhične odnose. Tako »ni priporočljivo« kritizirati nadrejenega, nadrejeni sam pa se na tak način ne zave lastnih napak $v$ odnosu do posameznika. Ker jih ne pozna, se jih tudi ne znebi in se iz njih nič ne nauči. Pogosto se namreč dogaja, da nadrejenemu ali sodelavcem ne povemo, kaj delajo narobe, kakšne negativne odzive povzročajo. Kako naj potem pričakujemo, da se bodo spremenili in delali drugače (učinkoviteje).

$\checkmark$ ta sklop sodi tudi obveščanje sodelavcev o pomembnih dogodkih, spodbujanje ali pozivanje podrejenih $\mathrm{k}$ pogovoru s predstojnikom, zbiranje mnenj o neki temi itd.

\subsection{Odnos posameznika do delovnega okolja}

Delovni sistem, $v$ katerem deluje posameznik, lahko preprosto definiramo kot vse tisto, kar ni znotraj meja njegovega delovnega sistema. Poznamo več vrst okolja, osnova pa je delitev na zunanje in notranje okolje.

Zunanje okolje so državljani, ki pričakujejo storitve upravne organizacije, splošno politično okolje, ekonomsko okolje, podjetniško okolje, interesne skupine itd. Notranje okolje sestavljajo predvsem drugi zaposleni $v$ upravni organizaciji, s katerimi posameznik nima rednih vsakodnevnih stikov, in seveda tudi vodstvo upravne organizacije. 


\section{Janez Stare}

\section{Vloga posameznika pri spreminjanju javne uprave}

$\checkmark$ delovni praksi se odnos posameznika do okolja in s tem možnost vpliva na povečanje učinkovitosti dela kaže predvsem pri delu s strankami in javnostjo. $V$ zvezi s tem praviloma govorimo o ustreznem nivoju storitve, ki jo nudimo stranki in javnosti. Pri tem so področja dela raznolika, posebno pomembna pa so tista, ki omogočajo gradnjo pozitivne podobe upravne organizacije $\vee$ javnosti. Ravnanje posameznika mora izhajati iz zavedanja, da kot javni uslužbenec deluje $v$ javnem interesu. Tako se $v$ vsaki situaciji od njega pričakuje, da ravna do vsakogar in v vseh primerih pošteno, pravično, nepristransko in dostojanstveno.

Zavedanje, da se učinkovitost upravnega dela povečuje tudi z zadovoljstvom strank, je pomembno. Pri tem je pomembno vprašanje, kako ugotavljati zadovoljstvo strank s storitvijo in razumeti, kakšno je mnenje stranke o opravljeni storitvi. Močan vpliv na ocenjevanje kakovosti storitve ima namreč zaznavanje, saj se stranka odziva čustveno. Zato ni pomembna le sama strokovnost opravljene storitve, ampak tudi, kako se stranka odziva med izvajanjem in po končani storitvi.

\section{Posameznik in proces graditve organizacijske kulture}

Oblikovanje in zavedanje odnosov, ki smo jih definirali v prejšnjem poglavju, bosta lažje in hitreje dosegli svoj namen, če ju bo spodbujala organizacijska kultura posamezne upravne organizacije. Organizacijska kultura je eden od pomembnih dejavnikov učinkovitosti organizacije, saj vpliva na način organiziranja dela, ravnanja s človeškimi viri, vodenja, nadzorovanja, načrtovanja, komuniciranja itd. Weihrich in Koonz (1994, str. 716) definirata organizacijsko kulturo kot splošni obrazec obnašanja, verovanja in vrednot, ki so skupni pripadnikom neke organizacije.

Beseda kultura ima različne pomene in se uporablja tudi v povezavi z organizacijami, skupinami in timi. Schein (Schein, 1995, str. 21-22) definira glavne kategorije, ki lahko asociirajo na kulturo:

- ponavljajoči se odnosi in interakcije; jezik, navade, tradicija in $v$ mnogih situacijah uporabljeni rituali;

- skupinske norme; implicitna merila in vrednote, ki se razvijejo znotraj skupin, kot je npr. pošteno plačilo za pošteno delo;

- izražene vrednote; artikulirani in javno predstavljeni principi in vrednote, po katerih se skupina po lastnem prepričanju ravna, npr. kakovost izdelkov;

- javna filozofija; zajeta politika in ideologija, po kateri se skupine pri ravnanju in občevanju s sodelavci, strankami in drugimi odločilnimi ljudmi ravnajo;

- pravila igre; gre za tihi sporazum, po katerem se sprejmejo pravila za življenje $\vee$ organizaciji; novi člani se jih morajo najprej naučiti, če želijo, da jih bodo sodelavci sprejeli; gre za način, kako "stvari pri nas potekajo«; 
- klima; kaže se $v$ vzdušju in oblikah medsebojnega shajanja pripadnikov organizacije kot tudi $v$ ravnanju $s$ strankami in $v$ drugih zunaj nastajajočih razpoloženjih znotraj organizacije, skupine ali tima;

- zakoreninjeni talenti; posebne sposobnosti, ki jih člani skupine potrebujejo za opravljanje nalog; lahko se prenašajo iz generacije $\vee$ generacijo in ni treba, da so zapisane;

- miselne navade, duhovni modeli in/ali jezikovne paradigme; skupni kognitivni okviri, zaznavanje, mišljenje in sporazumevanje,

- skupni pomen, ki nastane po dogovoru članov skupine,

- simboli; imajo integracijsko moč.

Organizacijska kultura pomeni način mišljenja, razmišljanja in občutkov $\vee$ organizaciji. Gre za poseben, organizaciji lasten način emocionalnega reagiranja, ki se povezuje z vprašanjem, kako odvračati strah in kako vzbuditi veselje. Je ključ do razumevanja organizacije, pri čemer je treba še posebej upoštevati vsakega posameznega uslužbenca. Brezovšek (Brezovšek, 1997, str. 184) meni, da gre za velike preizkušnje, ki so tudi kulturno determinirane, saj $\vee$ slovenski politični in upravni kulturi lahko najdemo pripisovanje krivde za svoje slabosti drugim, pomanjkanje duha zakonov, dajanje prednosti kratkoročnim ciljem pred dolgoročnimi, odpor proti spremembam, antiintelektualizem idr. Odgovor glede spodbujanja učinkovitosti uprave od posameznika je treba iskati na ravni posameznika in njegovega dojemanja pričakovanih in zahtevanih sprememb ter okolja (kulture) upravnega delovanja.

Iz organizacijske kulture se lahko ugotovi, kakšno je stanje $v$ organizaciji, poleg tega neformalno oblikovana kultura dostikrat bolj določa ravnanje $v$ organizaciji kot vsi pravilniki. $V$ svojih namerah so praviloma propadle vse organizacije, ki so s pravili in z okrožnicami poskušale urejati slabe medsebojne odnose. Prav to dejstvo pa potrjuje prepričanje, da je pot do uspešnih sprememb javne uprave $v$ ljudeh in $\vee$ graditvi kulture, ki se zaveda pomena tistega, kar posameznik stori ali česar ne. Dejanje ali tudi tisto, česar posameznik ne stori, je izoblikovano na osnovi notranjih, njemu lastnih odnosov do različnih področij (so)delovanja. Prav omenjeni vidik pa smo želeli poudariti v prispevku.

\section{Zaključek}

Učinkovitost javne uprave je opredeljena kot zmožnost javne uprave, da opravlja, kar se od nje pričakuje. Vplivi na spreminjanje in povečevanje učinkovitosti so različni tako glede na zaposlene kot na naravo njihovega dela. $V$ tem procesu imajo posamezniki pomembno vlogo.

Spodbujanje in povečevanje učinkovitosti upravnega dela z aktivnostjo posameznikov je mogoče po različnih kriterijih. Upoštevanje le nekaterih bi bilo zelo pomanjkljivo. Zaradi velikega števila dejavnikov tudi ni mogoče podati enotnega "recepta", ki bi zagotavljal učinkovitost upravnega dela. Posameznik mora zato 


\title{
Janez Stare \\ Vloga posameznika pri spreminjanju javne uprave
}

dobro poznati sebe, svoje delo, upravno organizacijo in njene cilje ter potek dela, s svojim odnosom do strank pa mora graditi pozitivno podobo javne uprave. Takšen vidik delovanja je možno spodbuditi s spremenjeno kulturo upravnega delovanja.

\section{Literatura in viri}

- Bandelj, M. (1998): Analiziranje učinkovitosti državne uprave, Analiziranje za potrebe strateškega določanja ter dosežki analitske prakse teorije. Zbornik referatov 1998. Zveza ekonomistov Slovenije, Portorož, str. 130-145.

- Brajša, P. (1993): Pedagoška komunikologija. Glotta Nova, Ljubljana.

- Brejc, M. (2000): Ljudje in organizacija v javni upravi. Visoka upravna šola, Ljubljana.

- Brezovšek, M. (1987): V: Demokracija - vladanje in uprava v Sloveniji, Zbornik referatov. Politološki dnevi, Portorož, 6. in 7. junij 1997. Slovensko politološko društvo, Ljubljana, str. 175-187.

- Bučar, F. (2000): Bo javna uprava po reformi drugačna? Zbornik referatov. VII. Dnevi slovenske uprave, Portorož 2000. Visoka upravna šola, Ljubljana, str. 39-45.

- $\quad$ Everard, B., Morris, G. (1996): Uspešno vodenje. Zavod Republike Slovenije za šolstvo, Ljubljana.

- Heraty, N., Morley, M. (1998): In search of good fit: policy and practice in selection in Ireland. Journal of Management Development, Vol. 17, št. 9, str. 662-685.

- Jelenc, S. (1996): ABC izobraževanja odraslih. Andragoški center Republike Slovenije, Ljubljana.

- Kranjc, A. (1982): Motivacija za izobraževanje. Delavska enotnost, Ljubljana.

- Kovač, P. (1999): Tradicionalno in novo upravljanje javnega sektorja - primer upravnih enot. Javna uprava, št. 1/1999, Ljubljana, str. 29-48.

- Kodeks ravnanja javnih uslužbencev. Uradni list RS, št. 8-474/2001.

- Republika Slovenija (2001). Strategija Republike Slovenije za vključitev v Evropsko unijo, 7. reforma javne uprave. http://www.gov.si/svez/strategija/. 20. 4. 2001.

- Republika Slovenija, Urad za informiranje (2001). Poročilo Evropske komisije o napredku Slovenije pri vključevanju v Evropsko unijo. http://evropa.gov.si/iso/ceu_026_5.html. 20. 4. 2001.

- Robbins, P. S. (1998): Organizational Behavior, Concepts, Controversies, Applications. New Jersey: Prentice-Hall International, Inc.

- $\quad$ Schein, E. H. (1995): Unternehmenskultur, Ein Handbuch für Führungskräfte. Campus.

- Thorrington, D., Hall, L. (1995) Personnel Management, HRM in Action, 3. izd. New York, London, Toronto, Sydney, Tokyo, Singapore, Madrid, Mexico City, Munich, Hertfordshire: Prentice Hall.

- Tekavčič, M. (2000): Uravnoteženi sistem kazalcev uspešnosti poslovanja, 1. del. Gospodarski vestnik, d. d., Ljubljana, številka 26, 29. 6. 2000, str. 59.

- Weihrich, H., Koontz, H. (1994): Menedžment. MATE, Zagreb.

\begin{abstract}
Janez Stare je magistriral na področju kadrovskoizobraževalne dejavnosti. Zaposlen je kot višji predavatelj za organizacijsko-kadrovsko področje na Fakulteti za upravo Univerze v Ljubljani. Pri svojem pedagoškem in raziskovalnem delu se ukvarja z ravnanjem s človeškimi viri in razvojem človeških virov, metodami in tehnikami upravnega dela, upravnim poslovanjem ter organiziranjem upravnih dejavnosti.
\end{abstract}




\section{SUMMARY}

\section{The Role of the Individual in Changing Public Admini- stration}

There are a number of factors prompting calls for the modernisation of Slovenia's public administration; these factors include the demand for the more efficient functioning of state institutions and the country's imminent accession to the European Union. In assessing the readiness of the candidate states, the European Commission often indicated the need for the continued development of administrative competence and improvements in the efficiency and effectiveness of public administration. Improving the efficiency of the functioning of public administration must become part of a new organisational culture that reflects daily efforts by employees to promote and improve the efficient functioning of the their departments. Here questions arise as to whether there exist individual ways of promoting the efficiency of public administration functioning that can be given a general definition for all civil servants, irrespective of their position or status.

The efficiency of the public administration can be gained by abandoning the bureaucratic model (the Weber model) that is most typically found in the sphere of public administration. Given its assumption that an organisation functions as a closed system that does not include mechanisms to adapt to changes in the environment, a Weber type organisation is no longer adequate to deal with new circumstances in public administration. Instead, we have seen the rise of the principles of New Public Management (NPM) in the public administrations of developed democracies, particularly over the last decade. NPM takes as its starting point the idea that the positive experiences of private sector management should be introduced into the functioning of public administration. In this manner we can expect that public administrations will also be capable of attaining and adopting the characteristics of successful organisations. The individual has a special role in this process for two reasons. Firstly, it means that professionally the work of an individual is at a higher level, so the individual's work has an important effect on the course and effectiveness of the public administration's functioning. This leads to individuals being more and more valued, while their influence on the organisational process means they gain more authority. Secondly individuals are increasingly involved in working across different areas of public administration operations.

There are many factors affecting how and where an individual's influence on promoting the efficiency of public administration is most evident. We can 
Janez Stare

Vloga posameznika pri spreminjanju javne uprave

divide them into five basic groups that define the work and attitudes of the individual to: his or herself, his or her own work, the organisation, colleagues, the working environment.

The individual's attitude to him or herself is a basic condition for the individual to follow rapid development in public administration and participate on an equal basis in new working conditions. This concerns the individual's thoughts on continuous training and the enhanced competence of the individual in all areas of life and work.

When speaking of the individual's attitude to his or her own work as a factor in promoting the efficiency of public administration, one is pointing primarily to the definition of key areas of the individual's work, assignments and the rules that must be respected at work. Of course, we cannot neglect what was stated above: the individual's concern for personal development. The difference is that the attitude to oneself involves training and general competence, while in the attitude to one's own work we are interested in a person's capacity to do the work for which he or she is currently responsible.

If an individual wants to make a full contribution to the efficiency of the public administration, he or she must be familiar with the system of public administration and its functioning. The individual's attitude to the organisation (the public administration) falls within this framework. They must understand and function in line with the objectives of the administrative organisation in which they work and, of course, in line with the objectives of their department, position and the objectives of their superiors.

The right attitude towards colleagues or co-workers facilitates right responses, cooperation, and encouragement among the workforce. Herein also lie opportunities to increase the administrative organisation's efficiency. The right attitude towards colleagues is normally defined by basic communication values, including respect, listening, acceptance and being aware of their interdependence.

The attitude of the individual to the working environment is addressed in relation to both the external and internal environment. The external environment is the public that expects services from the administrative organisation, the more general political environment, the economic environment, the enterprise environment, interest groups, etc. The internal environment consists, above all, of other employees of the administrative organisation that the individual does not have day-to-day contact with and, of course, the management of the administrative organisation. In working practice an individual's attitude to this environment - and with that the opportunity to increase work efficiency - primarily appears in work with clients and the public. 
Shaping the attitudes set out above and gaining familiarity with them will achieve their functions more quickly and easily if promoted by an appropriate organisational culture within an individual administrative organisation. The organisational culture is one of the most important factors in the efficiency of an organisation, as it has wide-ranging effects on the way in which work is organised, on human resource management, leadership, supervision, planning, and communicating. It is by looking at the organisational culture that one can ascertain the condition of an organisation; furthermore, it is far more often the informally developed culture that determines how an organisation acts than the organisation's rulebook. What individuals do or neglect to do is shaped by their internal, personal attitudes to various areas of work and cooperation. It is this very point that this paper is intended to highlight. 